\section{Insects On Parade}

\author{
Steven Coffman \\ Dundee, New York
}

Editors' Note: This memoir is one of 59 short chapters of $A$ Family Bestiary, animal stories recounting 22 years of living on a defunct farm in Yates County, New York.

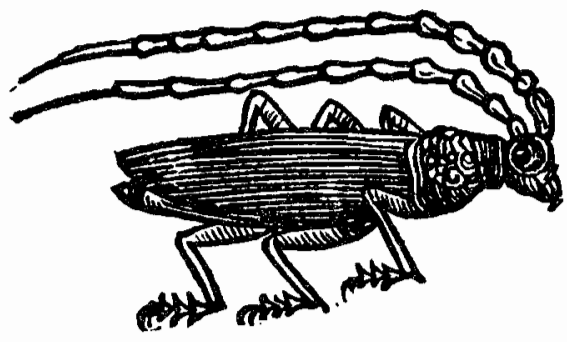

In addition to the garden being an attracter of certain creatures and an attracter of our attention to them, there were a few species that came to the garden because they were attracted to us. This category belonged almost exclusively to biting flies. I don't think they really new the garden as a special place and waited for us there. Rather, I think the scenario played itself over and over again in just the same way. While we were happily working away in one place, one or two of them happened upon our sweaty scent and then somehow rang the dinner bell for their compatriots, and we were suddenly inundated.

Our biting flies came in three waves: black flies in early June; noseeums in mid to late June; deerflies and horseflies in July and August.

Black flies, the gnat-size little devils, came in hordes...earlobes, eyelids and scalps being their most delectable pieces de resistance.

Noseeums, so called because of their pinpoint size, usually came out while the black flies were still there and stay for about a month. Despite the silliness of their name, a swarm of noseeums could also send one back to the house in short order. While their bites were not really painful, there was something psychologically

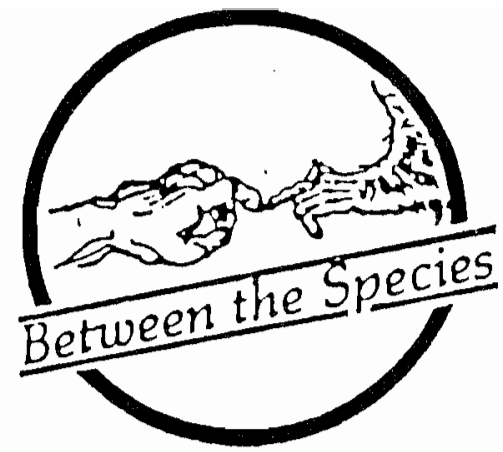

unnerving about frequent pinprick attacks coming from something you couldn't see or hear.

In direct contrast to noseeums, with deerflies and horseflies it was exactly their size and noise, their continuous flitting and buzzing that was so unsettling; especially since their bites were also considerably more painful, as soon as the buzzing lessened, one began to imagine them poised to bite on every rolling sweatdrop. The swept wing deerflies were especially a nuisance. Fortunately, the bumblebee-size horseflies-whose bites often drew blood and left strawberry welts-were fewer and more cautious about landing on humans, much preferring animals of barn and pasture.

Something there is that doesn't love an insect, I suppose. And yet, despite the fact that some of them sting, bite, spread disease, ruin crops, invade (even eat) our homes, I think our dislove for them has more to do with their smallness, the fact that we don't see them very well, which makes them seem sneaky. They move in and out of places where we can't see them. They leap, they crawl, they come through the air, they swim, they burrow, they look like rocks and twigs and leavessuddenly they're just there. Them! Not only are they too small for us to take them seriously as individuals, but they're also almost impossible to look in the eye. Looking something in the eye is the way that we judge its character and intent, the content of its soul. But only

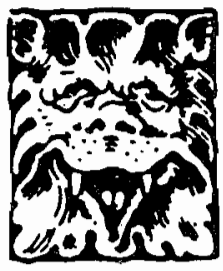


under magnification can we look an insect in the eye, and then-egad! - what comes back at us is the alien stuff of nightmares! Eyes that look everywhere at once but never meet ours. What kind of hellish nonsouls do these windows look into?

And not only are they sneaky small and impossible to individualize, but they come in hatches, hordes and hives, in too many varieties even for us to effectively catalogue.

What's more, because of their smallness, survival has required them to become outfitted with an enormous array of protective devices: gorgon faces, unsquashable armors, weapons both real and faux, camouflages so exact that some look like leaves and twigs right up to the nodes, veins and drops of dew. Thus, we can never be quite sure when they're with us and when they aren't, what we're dealing with and what we aren't.

And yet...one can get into a mood to admire insects: their antiquity, their magnificent adaptability, their ability to carry life's message in so many guises. They may seem alien and mechanical putting no value in the "one" except as a vassal of the "many,' but there's another way to look at it.

Because so few insect offspring ever live to reproduce, nature places great value on the mutant insect, the extraordinary individual who jumps a little higher, flies a little faster, hides a little better, demonstrates or bluffs a greater repugnance or ferocity. Any change that increases the chance of survival is more likely to be reproduced; and it's because insects reproduce so often and in such great numbers that there are so many insect species with so many diverse abilities; billions of tiny changes continually maximize insect changes to be the right individual in the right place and time to survive and reproduce. Insects have been Evolution's darlings for a billion years expressly because of the importance of "individual" changes. This may even be seen as Evolution's way of ensuring that the weak inherit the earth.

In fact, we certainly need insects much more than they need us. They have carried life's banner almost from the beginning into the present and continue to be a great part of the natural balance that sustains us.

Even esthetically we would greatly miss them. Not only because they pollinate flowers, make honey, and are food for fish and birds-we would miss them in their own right. Biting flies and mosquitoes may come in waves and hatches, but so do Junebugs, lightning bugs, dragonflies, butterflies, and August's culminating euphonic pulse of crickets, katydids and mantises that has left its imprint in us...one of the haunting soulfilling places where music comes from.

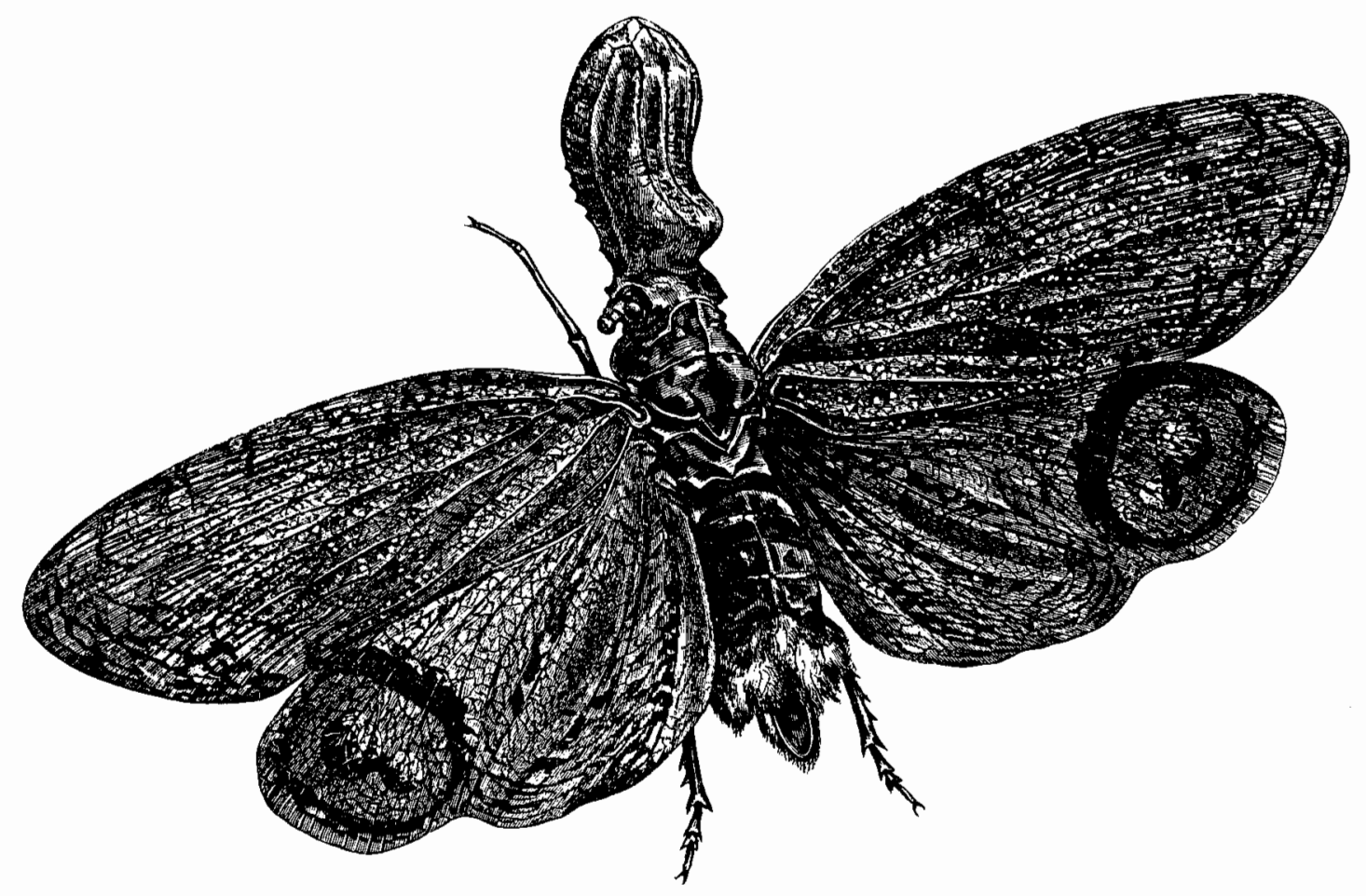

